\title{
Urgences
}

\section{J'avais un frère}

\section{Jean-Yves Dupuis}

Numéro 5, 3e trimestre 1982

URI : https://id.erudit.org/iderudit/025078ar

DOI : https://doi.org/10.7202/025078ar

Aller au sommaire du numéro

Éditeur(s)

Urgences

ISSN

0226-9554 (imprimé)

1927-3924 (numérique)

Découvrir la revue

Citer ce document

Dupuis, J.-Y. (1982). J'avais un frère. Urgences, (5), 61-66.

https://doi.org/10.7202/025078ar

Ce document est protégé par la loi sur le droit d'auteur. L'utilisation des services d'Érudit (y compris la reproduction) est assujettie à sa politique d'utilisation que vous pouvez consulter en ligne.

https://apropos.erudit.org/fr/usagers/politique-dutilisation/
Cet article est diffusé et préservé par Érudit.

Érudit est un consortium interuniversitaire sans but lucratif composé de l'Université de Montréal, l'Université Laval et l'Université du Québec à Montréal. Il a pour mission la promotion et la valorisation de la recherche. https://www.erudit.org/fr/ 


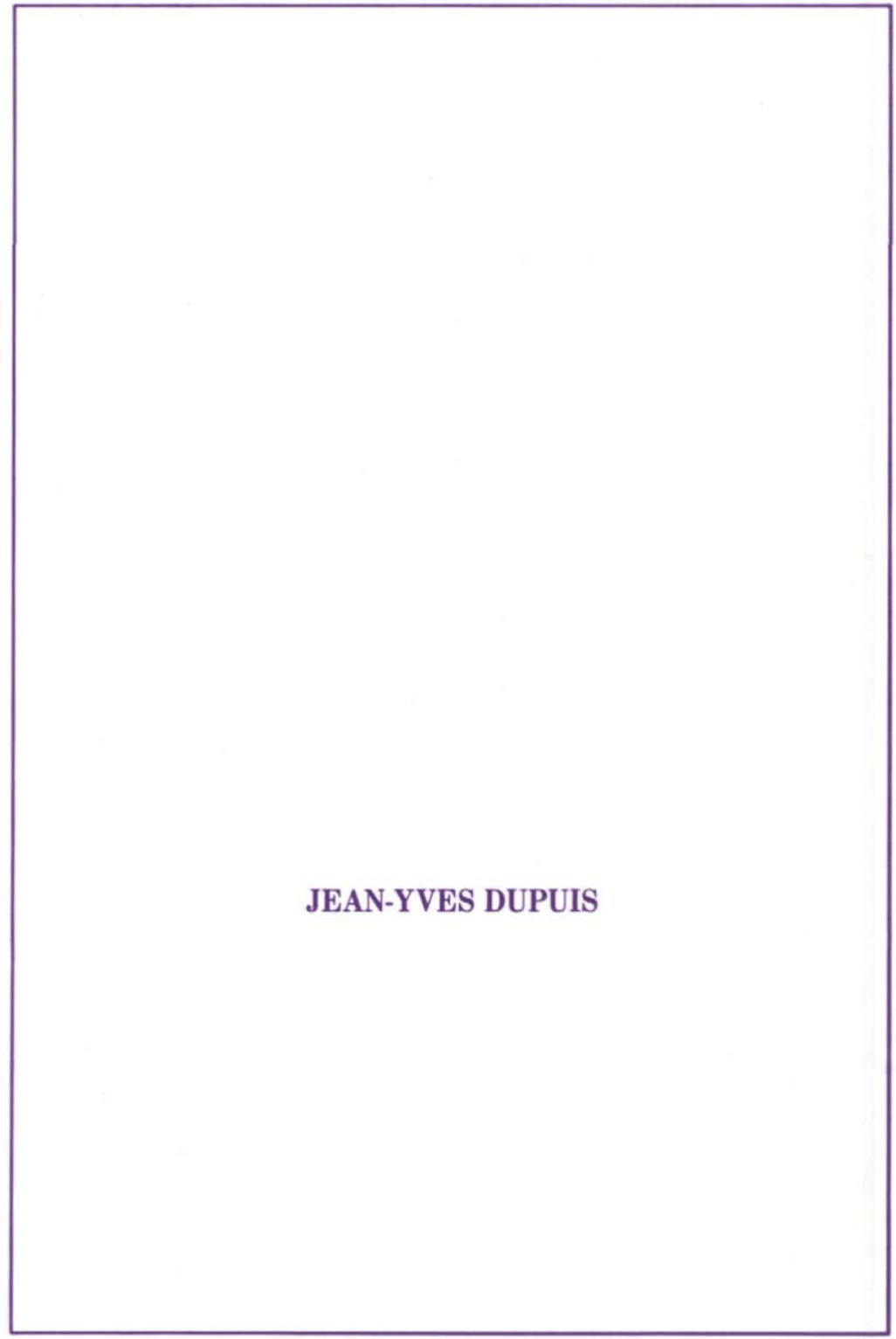




\section{J'AVAIS UN FRĖRE}

Mon frère est mort depuis bientôt trois ans. Une petite grippe, ou une maladie de poitrine, je ne sais pas exactement, les derniers jours il était vert, ne mangeait plus, et puis il toussait constamment. Je l'ai soigné, lavé, nourri, du mieux que j'ai pu, d'autant qu'il était aveugle de naissance, j'en avais un peu l'habitude. Il avait plus souvent besoin de moi que moi de lui, mais sa maladie a dérangé mon petit train-train quotidien, vous savez les malades ça indispose toujours un peu, mais je m'y suis fait, ce n'était pas un méchant bonhomme après tout.

Je l'ai enterré dans le jardin, comme ça, sans manière, sans consulter personne, sans messe interminable, et tout le bataclan, à quoi ça sert les cérémonies? Et puis, je me demande bien où j'aurais pu prendre l'argent, on n'a plus les moyens de mourir aujourd'hui, les tombes? un prix exorbitant. Tandis que le jardin, la bonne terre de chez nous, il aurait sûrement préféré ne pas trop s'éloigner de la maison paternelle, il n'a pas cessé d'en faire partie encore, de la maison je veux dire. Moi de le savoir là me réconforte, je lui parle, je lui tiens compagnie, et puis je sais qu'il y a toujours quelqu'un couché là sous les tomates, c'est bizarre moi je n'ai jamais pu souffrir la solitude.

Je ne sais pas pourquoi j'ai toujours aimé m'entourer de vieilleries, de livres, de disques, de bibelots sans importance mais qui me rappellent un moment précis de ma vie, j'ai toujours été un peu sentimental, les objets ça fixe le passé. De lui dans le jardin, je garde quelque chose: son pouce droit que j'ai décroché de sa main et que je conserve maintenant dans un bocal de formol. Souvenir et souvenir, je me serais contenté largement de le savoir là derrière la maison, mais voilà ce pouce a aussi un but utilitaire. Comme j'ai toujours été un peu serré du côté argent quand mon frère vivait, l'argent qu'il retirait de sa pension de retraite suffisait amplement à nous nourrir tous les deux, nous n'avions pas grands besoins - je me suis dit qu'il n'était pas possible de me passer de cet argent qui nous faisait vivre depuis si longtemps. Comme mon frère ne pouvait pas écrire même son nom, j'avais I'habitude de remplir moi-même les formulaires, et lui 
signait avec son empreinte, nous retirions alors le chèque. Si j'avais pu fournir encore cette signature, on n'y aurait vu que du feu, et alors j'aurais pu encaisser l'argent, car qui savait que mon frère était bien mort et enterré là dans le jardin?

Les doigts isolés, décrochés de leur main propriétaire, ça m'a toujours un peu écoeuré. Dans la blessure, il y a une couche de sang figé, rouge, sale, et puis aussi la naissance de l'os, mais enfin, tant pis, un pouce c'est un pouce, quand je le sors de son contenant, toutes les fois il me vient un haut-le-coeur, mais c'est passager, je suis de petite nature. Pourtant ça ne m'a sûrement pas empêché de faire ce qu'il faut, enduire le pouce d'encre, et déposer l'empreinte sur la feuille de papier. Une signature bien propre, qui pourrait deviner? Chaque mois, je reçois un chèque confortable.

A y penser, c'est idiot ce que j'ai fait, j'aurais sûrement trouvé un moyen, un petit travail, pas trop exigeant, qui m'aurait permis de vivre. Mais un travail, pas que je sois paresseux, non, je n'ai pas le temps de travailler, qui s'occuperait de la maison, et du jardin? Et I'habitude, j'ai perdu I'habitude de travailler, de recevoir des ordres, rien ne vaut d'être son propre chef, s'arrêter quand on le désire, suivre son rythme. Dire que je dois toute cette tranquillité à laquelle je me suis depuis longtemps habitué à... à un pouce, le pouce de mon frère, ha! ha, ils ne sont pas nombreux ceux qui doivent gagner leur vie grâce aux pouces des autres, je les ai roulés toutes ces années, sans qu'ils s'aperçoivent de rien. S'ils savaient!... S'ils découvraient la véritél... Ah, mais ils se tordraient de rire, a-t-on déjà vu pareille escroquerie, couper le pouce de son frère, et... et... Mais c'est d'un ridicule! Hal ha!

Enfin! Tout de même! Je ne vais pas aller le crier sur tous les toits, ce n'est le droit de quiconque de savoir. Tant que I'affaire restera entre moi et... et le fond du jardin, je n'ai pas à m'inquiéter, et puis... qui viendrait s'y mettre le nez, depuis le temps qu'on ne s'intéresse plus à ce que je fais. Trop occupés ceux-là à inventer leurs mauvaises histoires, et à se les répéter, si bien 
qu'elles arrivent jusqu'à moi. Je les aperçois avec leurs yeux fouineurs. Ils préfèreront me trouver mille vilains défauts qu'une seule qualité. Et tant pis pour eux, je n'ai rien à leur dire. Qu'ils restent donc chez eux!

Mais ... quand faudra-t-il le faire mourir, lui, mon frère? II ne suffira pas de le tuer sur papier, là sur tous ces formulaires, ils viendront contrôler, et toutes leurs questions, et leur curiosité, ils voudront voir, et puis les gens du village, quand ils entendront parler d'une mort, ils ouvriront toutes grandes leurs sales oreilles, à l'affût des moindres petites histoires, ils finiront par savoir... Non! Que pourrais-je inventer?... En fait, le seul point qui m'inquiète. Et puis... qu'est-ce que je dis? II vivra cent ans, mon frère, solide, solide comme le roc. II peut vivre aussi longtemps que moi. Qu'est-ce qui pourrait l'en empêcher? Ha! ha! Oui, je sais bien que si j'oubliais le pouce sur ma table de travail pendant toute une semaine, la décomposition, et alors! C'en serait fait de ma petite combine, mais je me demande bien pourquoi il $\mathrm{m}$ 'arriverait pareille aventure, je n'ai à m'inquiéter de rien, je peux dormir sur mes deux oreilles. Maintenant je vais aller remuer le jardin. 


\section{LA GALERIE}

Pas le temps de mettre le pied dans l'escalier qui mène chez moi qu'il est là à me dévisager de son regard sans expression, un homme très vieux, c'est mon voisin, du matin au soir sur sa galerie qui est aussi la mienne, éternellement à surveiller la rue, les gens, et quand je rentre chez moi, il me surveille du coin de son oeil sans jamais dire un mot. Son visage ne dit rien, je ne sais s'il peut être content quelquefois, ou s'il lui arrive de rire, mais sa bouche est toujours fermée, ses yeux grand ouverts, il examine, il décortique chaque passant, les prend à part, les dévore jusqu'à ce qu'ils aient tourné le coin de la rue.

Ce soir, encore là, comme à son habitude, je sens ses yeux sur moi, et je ne sais, la fatigue ou le soleil, mais je veux briser ce visage, je veux lui dire un mot pour le voir réagir, mais je ne trouve rien, tout reste pris dans ma gorge parce que ces yeux-là m'absorbent, m'interdisent de parler, ces yeux me font peur. C'est idiot! Alors pour dire quelque chose, j'ai dit: Bonsoir. II a marmonné un mot péniblement et a continué de surveiller la rue. Je me suis réfugié chez moi.

Quoi que je fasse ce soir, ce vieux-là tient ma tête, je le sens à proximité pour m'espionner. J'essaie de lire, mais j'entends le bruit de sa berceuse sur la galerie, et alors je me l'imagine à regarder dans mon salon pour me juger, me condamner sûrement. Je sais bien que c'est impossible, il ne rentre jamais chez moi, mais cette peur que j'ai toujours le savoir là à ma porte. L'appartement est trop petit, pour lui et moi, je veux être seul, je vais me fondre dans la foule de la rue, même si je dois l'affronter encore un instant. Je sors de chez moi sans rien voir, je presse le pas, je disparais.

II était là encore cet autre soir, avec ces mêmes yeux, à ne rien dire, et il m'a regardé jusqu'à ce que je sois bien caché chez moi. Je n'en peux plus de le voir toujours là, je me sens volé. S'il disait un mot, je pourrais me fondre une image, et me dire: C'est un vieux comme les autres, ou selon: C'est un original, il a ses petites fantaisies, mais non il ne dit jamais rien, 
à personne, je ne sais rien de lui. Et il regarde toujours la rue, sans jamais se lasser.

Cela a assez duré. Je ne me ferai pas prendre ainsi continuellement. II faut que je fasse quelque chose, l'aborder, l'interroger sur sa vie, ou le temps qu'il fait, ou n'importe quoi d'autre. Ou bien je pourrai aussi l'insulter abondamment. Qu'importe, il faut qu'il réagisse ne serait-ce qu'un instant, j'ai besoin d'un sourire ou d'un mot ou d'une insulte de lui, j'en ai terriblement besoin. Et qu'il cesse enfin de me regarder avec ces yeux tranchants. Cela devraient être interdit de regarder les gens de cette façon. 